\title{
MANUTENÇÃO E REVISÃO DA MICOTECA DO PROGRAMA DE PESQUISA DE BIODIVERSIDADE DO SEMI-ÁRIDO BRASILEIRO - PPBIO
} 2011-2012

\author{
Mell Caroline Oliveira Amorim¹; Carolina Silva Ribeiro²; Luís Fernando \\ Pascholati Gusmão ${ }^{3}$ \\ 1.Bolsista PIBIC/CNPq, Graduanda em Bacharelado em Ciências Biológicas, Universidade Estadual de Feira de \\ Santana, e-mail: mellc.oliveira@gmail.com \\ 2. Bolsista DTI-3/PPBIO/CNPq, Universidade Estadual de Feira de Santana, e-mail: crsilvabio@gmail.com \\ 3. Orientador, Departamento de Ciências Biológicas, Universidade Estadual de Feira de Santana, e-mail: \\ lgusmao.uefs@gmail.com
}

PALAVRAS-CHAVE: Coleção; microfungos; semiárido.

\section{INTRODUÇÃO}

As micotecas são coleções de fungos mantidos para estudo futuro, que preservam o material biológico a fim de manter suas propriedades morfofisiológicas, químicas e genéticas, por isso, detêm grande importância para o desenvolvimento de pesquisas biotecnológicas em todo o país (Diogo et al., 2005). Como parte do patrimônio natural ex-situ detém grande valor para efetivar projetos de pesquisa que incluem linhas de estudo com fármacos, controle ambiental e biotecnologia (Camara et al., 2008). As coleções de cultura permitem o desenvolvimento de estudos básicos ou aplicados disponibilizando informações sobre fitopatógenos que podem ser aplicadas na melhoria de métodos de manejo, culminando no controle de doenças (Finatti \& Aparecido, 2009). Considerando a importância da manutenção da viabilidade das culturas fúngicas preservadas em coleções, pode-se perceber a necessidade dos estudos das técnicas de preservação desse material que permitirão avanços nos estudos biológicos (Passador, 2010). Este trabalho teve por objetivo a manutenção da Coleção de Cultura de Microfungos do LAMIC, através de reativação, revisão das características originais através de análise de lâminas e preservação dos espécimes fúngicos inseridos no acervo entre os anos de 2011 e 2012.

\section{METODOLOGIA}

O presente trabalho foi realizado no Laboratório de Micologia da Universidade Estadual de Feira de Santana (LAMIC/UEFS). Inicialmente foi realizado um levantamento para obtenção de informações sobre a quantidade de espécies e número de acessos nos anos de 2011 e 2012, seguida da reativação dos fungos do acervo. Os espécimes preservados pelo método de Castellani (em água destilada estéril) (Castellani, 1939 apud Figueiredo, 1967), foram reativados retirando um plug, contido no frasco com água destilada estéril, e colocado em placa de Petri esterilizada com papel filtro para secagem, e posterior acondicionamento em placa de Petri estéril com meio de cultura nutritivo. Para a reativação dos espécimes preservados em óleo mineral, o tubo com óleo foi colocado invertido em copo plástico de $200 \mathrm{~mL}$, para o escorrimento total do óleo mineral; após esta etapa foi retirado uma porção do meio de cultura e acondicionado em uma nova placa de Petri estéril com meio de cultura nutritivo. Todas as atividades de reativação foram desenvolvidas seguindo as recomendações de desinfecção, com utilização de bico de Bunsen e/ou lamparina a álcool e fluxo laminar. Após verificar a formação das estruturas reprodutivas nas culturas reativadas, estas passaram pelo processo de autenticação: confecção de lâminas, observação das estruturas de importância 
taxonômica em microscópio de luz, averiguação dos dados no banco de dados da coleção e comparação com a bibliografia pertinente à cada espécie para confirmação de sua identidade. Os fungos autenticados foram reinseridos na coleção pelos os dois métodos já citados: i) método de Castellani, em triplicata; ii) e em óleo mineral, em quintuplicata. Para a reinserção dos fungos pelo método Castellani, foram retirados 5-6 plugs de colônias puras jovens e esporuladas (entre 10 a 15 dias) e acondicionados em frascos de vidro (tipo penicilina) com $4 \mathrm{ml}$ de água destilada esterilizada, fechados hermeticamente e etiquetados. Para a reinserção dos fungos em óleo mineral, os espécimes foram repicados para tubos de ensaio contendo o meio de cultura e levados para uma BOD para crescimento e esporulação, e após a constatação da pureza do isolado, foi adicionado o óleo mineral estéril nos tubos. A manutenção por réplicas dos espécimes é de suma importância e potencializa a capacidade de conservação dos mesmos, além de minimizar os riscos de contaminação, bem como alterações morfofisiológicas e genéticas, em decorrência de mutações acumuladas ao longo das sucessivas repicagens (Abreu \& Tutunji, 2004). Ao longo desse processo, o banco de dados da coleção de cultura foi atualizado.

\section{RESULTADOS E DISCUSSÃO}

No levantamento inicial realizado, foram obtidos os seguintes dados: 162 espécimes do ano de 2011 (nove espécimes não foram encontrados) e 466 espécimes (nove espécimes não foram encontrados) para o ano de 2012 (Figura 1). Dos 628 fungos que compõem a coleção no período proposto (2011 e 2012), 236 fungos passaram pela manutenção, 162 preservados em 2011 e 74 em 2012 (Figura 2). Destes foram reinseridos 65 espécimes sem apresentar dificuldade na reativação, sendo 50 pertencentes ao ano de 2011 e 15 ao ano de 2012. Cerca de 98 espécimes não foram reinseridos, (40 isolados de 2011 e 58 isolados de 2012) por apresentar algum problema, como: ausência de crescimento quando repicados e/ou contaminação por outros fungos; no entanto, esses exemplares foram novamente lacrados e devolvidos à coleção. Os exemplares conservados em óleo mineral tendem a uma maior incidência de contaminação e inviabilidade quando preservados por longos períodos sem a devida manutenção, sendo mais atingidos em comparação aos conservados pelo método de Castellani. Devido a isso, foi preferível reativar os exemplares preservados pelo método de Castellani, e utilizando os preservados em óleo mineral apenas em casos onde não se conseguiu sucesso. Segundo Passador et al. (2010), a preservação pelo método de Castellani mantém a viabilidade e patogenicidade dos fungos durante longos períodos, e pode ser aplicado a uma ampla diversidade de espécies e com baixo custo. Entretanto, existem relatos de fungos preservados em óleo mineral que se mantiveram viáveis após 53 anos de preservação (Maciel, 2007). O método adotado para a preservação dos isolados da coleção deve ser o que melhor conserve a esporulação e patogenicidade do maior número de espécies (Aparecido \& Camilo, 2013). De maneira que se pode comprovar a eficácia na garantia da viabilidade dos métodos de preservação estudados. Outros métodos como, criopreservação e liofilização são também bastante utilizados dentre as coleções de cultura de fungos, no entanto, são extremamente dispendiosos financeiramente e não garante uma preservação para todos os grupos, podendo ocorrer perdas consideráveis de espécimes. A melhor forma de garantir a preservação de espécimes é a utilização de no mínimo dois a três métodos de preservação para cada espécime (Sola, 2011). 


\section{Dados da coleção de culturas de microfungos}

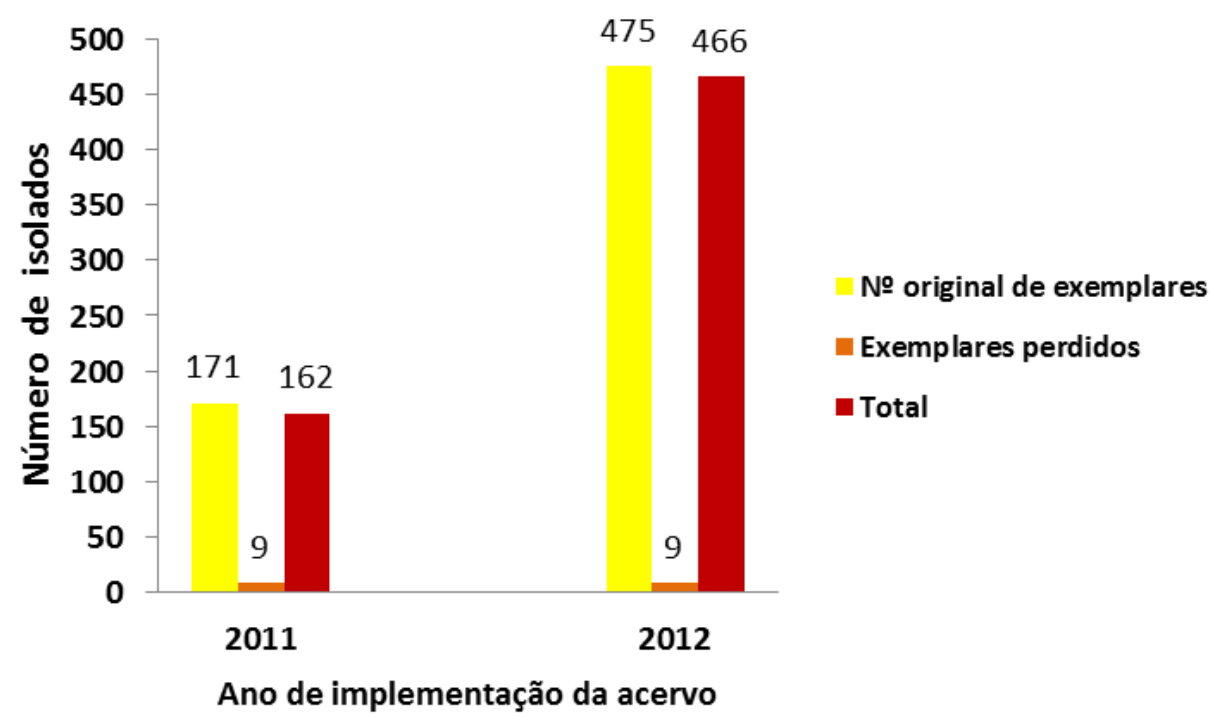

Figura 1. Número de isolados a serem reativados no período proposto (2011-2012).

\section{Gráfico da coleção de culturas de microfungos após a manutenção}

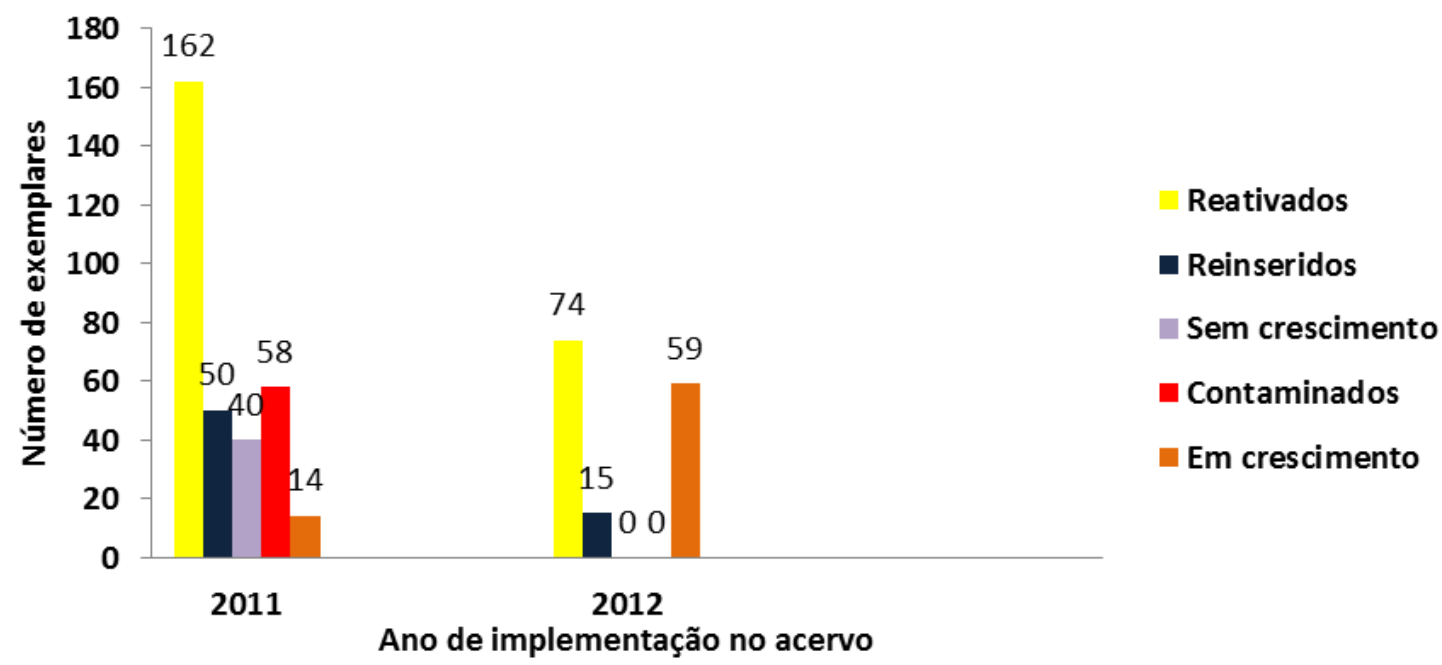

Figura 2. Resultados do trabalho de manutenção realizado no período de vigência da bolsa de Iniciação Científica.

\section{CONCLUSÃO}

Apesar da eficácia dos dois métodos de preservação utilizados na coleção de microfungos do LAMIC/UEFS, foi possível concluir que o tempo de conservação dos isolados influencia diretamente a viabilidade das culturas chegando a afetá-las de maneira irreversível, com contaminações e discordâncias na morfologia e fisiologia em relação à cultura original. Embora finalizado o período de vigência da bolsa de Iniciação Científica que contemplou este trabalho, continuam em processo de reativação cerca de 73 isolados, 14 (2011) e 59 (2012). A reativação dos isolados restantes será mantida para que haja prosseguimento da manutenção, visando o bom estado dos fungos componentes do acervo. 


\section{REFERÊNCIAS}

ABREU, M. M. V.; TUTUNJI, V. L. 2004. Implantação e manutenção da coleção de culturas de microorganismos do UniCEUB* Implantation and maintenance of microbial culture collection in UniCEUB*. Universitas Ciências da Saúde, 02(2):236-251. Disponível em:

<http://publicacoesacademicas.uniceub.br/index.php/cienciasaude/article/view/535/356 $>$

APARECIDO, C.C.; CAMILO, C.M. 2013. Comparação de métodos para a preservação fungos do gênero Colletotrichum em laboratório. Biológico, São Paulo, 75(1):17-22. Disponível em:〈http://www.biologico.sp.gov.br/docs/bio/v75_1/aparecido_camilo.pdf>

CAMARA, R. N.; GRANATO, M.; SA, M. R. 2009. As coleções microbiológicas e sua importância como patrimônio científico: o caso das coleções da Fiocruz. Pp. 303-314. In: Marcus Granato; Marcio Ferreira Rangel. (Org.). Rio de Janeiro: Cultura material e patrimônio da Ciência e Tecnologia.

DIOGO, H. C.; SARPIERI, A. \& PIRES, M. C. 2005. Preservação de fungos em água destilada* Fungi preservation in distilled water*. Anais Brasileiros de Dermatologia, 80(6): 591-4.

FIGUEIREDO, M. B. Estudos sobre a aplicação do método de Castellani para conservação de fungos patógenos em plantas. O Biológico, São Paulo, v. 33, n. 1, p. 913, 1967.

FINATTI, D.; APARECIDO, C. C. 2009. Caracterização fisiológica e comparação de diferentes métodos na preservação, em laboratório, de isolados do gênero Verticillium Arq. Inst. Biol., São Paulo, 76(4):715-720. Disponível em: < http://www.biologico.sp.gov.br/docs/arq/v76_4/finatti.pdf>

MACIEL, M. H. C.; MOTTA, C. M. S. 2007. 21215 - Viabilidade e confirmação taxonômica de isolados de espécies do grupo Aspergillus niger preservados sob óleo mineral na micoteca URM e caracterização genética por PCR-FINGERPRINTING. XV CONIC, XV Congresso de Iniciação Científica da UFPE. 29 a 31 de outubro de 2007.

PASSADOR, M. M.; PIRES, G. C. C.; FINATTI, D.; APARECIDO, C. C.; FIGUEIREDO, M. B. 2010. Divulgação técnica. Manutenção da viabilidade e patogenicidade de culturas mantidas na micoteca Mário Barreto Figueiredo. Biológico, v.72, n.1, p.51-55, jan./jun. São Paulo.

SOLA, M. C. 2011. Manutenção de microorganismos: conservação e viabilidade. Disponível em: 〈portais.ufg.br/uploads/67/original_semi2011_Marilia_Cristina_2.pdf> 